\title{
Recent Advances in the Assessment of Flood Risk in Urban Areas
}

\author{
Tiago Miguel Ferreira
}

ISISE, Institute of Science and Innovation for Bio-Sustainability (IB-S), Department of Civil Engineering, University of Minho, 4800-058 Guimarães, Portugal; tmferreira@civil.uminho.pt

Received: 23 June 2020; Accepted: 25 June 2020; Published: 29 June 2020

The adverse effects of flood disasters in urban areas have been increasing in severity and extent over the past years. The amounts of losses resulting from these events are also increasing exponentially, particularly in highly urbanised urban areas, where the effects of intensive land use and climate change are particularly extreme [1]. All this despite our scientific knowledge, technical competence and computational capacity to develop highly sophisticated and accurate forecasting and simulation models being higher than ever, as is our capacity to map and analyse flood-related data.

In order to tackle this global issue, it is fundamental to keep on promoting and developing fundamental and applied research that allows the better targeting of interventions to improve resilience, reduce vulnerability and enhance recovery, as well as assisting decision-makers in delivering more effective flood risk-reduction policies. The present Special Issue of Water aims to contribute to this goal by providing a space in which to share and discuss recent studies and state-of-the-art methodologies focused on the assessment and mitigation of flood risk in urban areas. It includes nine high-quality research articles authored by eminent scholars from India, Italy, Korea, Portugal, Romania, Singapore, Spain, Taiwan, Thailand and Vietnam, who had the tremendous generosity to join me in this project. The range of topics covered by these nine studies is extraordinarily vast, reflecting the complexity of the current challenges associated with the topic.

Lee et al. [2] present an interesting discussion on the role played by drainage facilities in urban flooding. Based on the analysis of a series of past flooding events, the authors propose a resilience index to be used to diagnose the status of urban drainage systems. Such an indicator, easily calculated using real-time rainfall data, allows for the identification of intervention needs and for the evaluation of the impact of structural and non-structural interventions aimed at reducing urban inundation - thus providing a proper means of supporting more efficient decision-making processes, fostering urban resilience.

Afifi et al. [3] propose a GIS-based high-resolution flood loss and risk assessment model to analyse the impacts of flooding events in residential urban areas. For such, different flood loss, hazard and vulnerability indicators - such as water depth, elevation, distance to first responders and population density-are combined using an Analytic Hierarchy Process (AHP). After being comprehensively presented and discussed, the model is used to generate a series of hazard, vulnerability and flood risk maps for the city of Tainan in Taiwan. Among other interesting particulars, the authors provide a critical discussion on the effects (measured in terms of estimated losses) of different spatial model resolutions.

Park and Lee [4] present a study aimed at contributing to the reduction and minimisation of flood damage in the case of heavy rainfall in urban areas, by increasing urban spatial efficiency through the grading of flood risk. To this end, the authors suggest an urban flood risk assessment model able to account for different urban planning elements, namely the land use and building characteristics. The capacities and the potential of the model are discussed through its application to Changwon City in Korea. The role played by land-use planning measures to prevent flooding, as well as the possibility 
of classifying flood risk areas according to the land use of the districts and of evaluating intervention priorities by selecting high-risk areas, are some of the aspects discussed by the authors.

Littidej and Buasri [5] analyse the way in which the Digital Elevation Model (DEM) and Flood Risk Susceptibility (FRS) prediction models are impacted by urban growth in Muaeng District, Nakhon Ratchasima (Thailand). The scope of this study comprises three main objectives: to optimise the Cellular Automata (CA) model for predicting the expansion of built-up sites, to model a linear regression method for deriving the transition of the digital elevation model (DEM), and to apply a Geographic Weighted Regression (GWR) for analysing the risk of the stativity of flood areas in the province. Among other noteworthy outcomes, this study shows that the CA model can accurately predict the expansion of built-up areas using land-use data updated at 2-year intervals.

Mihu-Pintilie et al. [6] develop a method for flood vulnerability assessment under real (average discharge) and mathematical (calculated discharge) hydrological data based on HEC-RAS, high-density LiDAR data, and 2D hydraulic modelling. The authors compute four 2D streamflow hydraulic scenarios in order to test the flood mitigation capacity of hydro-technical constructions located downstream on the Bistriţa River, North-East Romania. With this application, the authors show that multi-scenario results obtained from 2D hydraulic modelling can be applied to obtain flood hazard parameters (such as the flood depth, flood extent, flood velocity, or water surface elevation), which can be subsequently used in recognising and responding to flood threats at the local level.

Bernardini and Quagliarini [7] address the important issue of individuals' evacuation in urban flood scenarios by providing general and unified modelling approaches to estimate evacuation speed variations depending on an individual's excitement (walking or running), floodwater depths and individuals' features (age, gender, height and their average speed on dry surfaces). Speed data from previous experiments are organized using linear regression models. Finally, the authors discuss the possible implementation of these models to simulate evacuees' motion in floodwaters (considering different confidence degree levels) and to assess the community's flood risk and the effectiveness of risk-reduction strategies.

Dhara et al. [8] discuss the suitability of using different sources of satellite imagery for capturing the extent of flood inundation in urban areas. In this proof-of-concept study, the authors show that machine-learning algorithms—namely the Support Vector Machine Regression (SVR) technique — can be efficiently used to integrate data from three different satellite sensors (Landsat, MODIS and Sentinel-2) to derive one single integrated value. Because it relies on the use of freely available data, this approach constitutes an economical and efficient alternative, mainly when field data are not readily available, which is particularly frequent in regions with difficult access or with high rates of urban growth. The city of Can Tho (Vietnam) is used to prove the concept and to illustrate the potential of the approach.

Ferreira and Santos [9] discuss the application of an integrated flood risk assessment approach, which combines flood hazard and building vulnerability indicators to identify and classify risk and to narrow intervention priorities. The Historic City Centre of Guimarães, in Portugal, is exploited by the authors to illustrate the application of the methodology. After modelling the flood hazard using the hydrologic-hydraulic method and evaluating the flood vulnerability of the buildings by resorting to a simplified vulnerability assessment method, they provide a comprehensive analysis of the outputs in both an individual and integrated manner. Finally, they also use a risk-matrix approach to aggregate these hazard and vulnerability outputs and categorise the buildings into different qualitative levels of risk.

Arosio et al. [10] analyse the direct and indirect impacts of rainfall flooding in Mexico City. To do so, they resort to a graph-based methodology in which the exposed elements are organized as nodes on a graph that is used to propagate impacts from directly affected nodes to other nodes across network links. The authors discuss how the impacts are propagated along different orders of the impact chain for increasing return periods, also comparing the risk curves between direct and indirect impacts. Finally, they highlight the extent to which the reduction in the demand for services from consumers 
and the loss of services from suppliers are respectively contributing to the final indirect impacts, as well as how different impact mitigation measures can be formulated from these results.

I would like to express my sincere gratitude to the authors, who have kindly shared their scientific knowledge and experience through their contributions; to the peer reviewers, who have contributed to enhancing the quality of the articles published in this Special Issue; and to the managing editors of the journal, who have supported and promoted this project. Last but not least, I would like to leave a word of appreciation to the authors who, unfortunately, saw their manuscripts declined as a result of the high-quality standards adopted in the selection and review of the received articles.

Funding: This research was funded by the Portuguese Foundation for Science and Technology (FCT) through the postdoctoral grant SFRH/BPD/122598/2016.

Conflicts of Interest: The author declares no conflict of interest.

\section{References}

1. Miranda, F.N.; Ferreira, T.M. A simplified approach for flood vulnerability assessment of historic sites. Nat. Hazards 2019, 96, 713-730. [CrossRef]

2. Lee, E.H.; Choi, Y.H.; Kim, J.H. Real-Time Integrated Operation for Urban Streams with Centralized and Decentralized Reservoirs to Improve System Resilience. Water 2019, 11, 69. [CrossRef]

3. Afifi, Z.; Chu, H.-J.; Kuo, Y.-L.; Hsu, Y.-C.; Wong, H.-K.; Ali, M.Z. Residential Flood Loss Assessment and Risk Mapping from High-Resolution Simulation. Water 2019, 11, 751. [CrossRef]

4. Park, K.; Lee, M.-H. The Development and Application of the Urban Flood Risk Assessment Model for Reflecting upon Urban Planning Elements. Water 2019, 11, 920. [CrossRef]

5. Littidej, P.; Buasri, N. Built-Up Growth Impacts on Digital Elevation Model and Flood Risk Susceptibility Prediction in Muaeng District, Nakhon Ratchasima (Thailand). Water 2019, 11, 1496. [CrossRef]

6. Mihu-Pintilie, A.; Cîmpianu, C.I.; Stoleriu, C.C.; Pérez, M.N.; Paveluc, L.E. Using High-Density LiDAR Data and 2D Streamflow Hydraulic Modeling to Improve Urban Flood Hazard Maps: A HEC-RAS Multi-Scenario Approach. Water 2019, 11, 1832. [CrossRef]

7. Bernardini, G.; Quagliarini, E. How to Account for the Human Motion to Improve Flood Risk Assessment in Urban Areas. Water 2020, 12, 1316. [CrossRef]

8. Dhara, S.; Dang, T.; Parial, K.; Lu, X.X. Accounting for Uncertainty and Reconstruction of Flooding Patterns Based on Multi-Satellite Imagery and Support Vector Machine Technique: A Case Study of Can Tho City, Vietnam. Water 2020, 12, 1543. [CrossRef]

9. Ferreira, T.M.; Santos, P.P. An Integrated Approach for Assessing Flood Risk in Historic City Centres. Water 2020, 12, 1648. [CrossRef]

10. Arosio, M.; Martina, M.L.V.; Creaco, E.; Figueiredo, R. Indirect Impact Assessment of Pluvial Flooding in Urban Areas Using a Graph-Based Approach: The Mexico City Case Study. Water 2020, 12, 1753. [CrossRef] 